\title{
An anaplastic cardiac large cell lymphoma: A case report and analysis of cardiac involvement in newly diagnosed non- Hodgkin's lymphoma from the Czech Lymphoma Study Group (CLSG) database
}

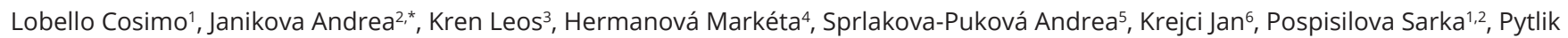
Robert ${ }^{7}$, Hamouzova Michaela ${ }^{7}$, Belada David ${ }^{8}$, Prochazka Vit ${ }^{9}$, Duras Juraj ${ }^{10}$, Mocikova Heidi' ${ }^{11}$ and Trneny Marek $^{7}$

${ }^{1}$ CEITEC - Central European Institute of Technology Brno, Masaryk University, Brno, Czech Republic

${ }^{2}$ Department of Internal Medicine - Hematology and Oncology, Faculty of Medicine, Masaryk University and University Hospital Brno, Brno, Czech Republic

${ }^{3}$ Department of Pathology, University Hospital and Faculty of Medicine, Masaryk University Brno, Czech Republic

${ }^{4} 1^{\text {st }}$ Department of Pathological Anatomy University Hospital St Anne and Faculty of Medicine, Masaryk University, Brno, Czech Republic

${ }^{5}$ Department of Radiology, University Hospital Brno, Czech Republic

${ }^{6} 1^{\text {st }}$ Department of Internal Medicine-Cardiology, University Hospital St Anne, Brno, Czech Republic

${ }^{7} 1^{\text {st }}$ Department of Medicine, First Medical Faculty, Charles University, and General University Hospital, Prague, Czech Republic

${ }_{8} 4^{\text {th }}$ Department of Internal medicine - Hematology, Charles University Hospital and Faculty of Medicine, Hradec Králové, Czech Republic

${ }^{9}$ Department of Hematology, University Hospital Olomouc, Olomouc, Czech Republic

${ }^{10}$ Department of Clinical Hematology, Teaching Hospital Ostrava, Ostrava, Czech Republic

${ }^{11}$ Internal Clinic of Haematology, University Hospital Kralovske Vinohrady, Prague, Charles University in Prague, $3^{\text {rd }}$ Faculty of Medicine, Prague, Czech Republic

\begin{abstract}
We report a rare case of anaplastic large cell ALK+ lymphoma (ALCL) with initial asymptomatic cardiac involvement. A 59-year-old male with infiltration of the right ventricular wall underwent standard combined chemotherapy (CHOP) and achieved remission without significant cardiac impairment. Additionally, we report the actual incidence of cardiac lymphoma in newly diagnosed non-Hodgkin Lymphomas (NHLs). In total, 16 patients with cardiac lymphoma were found $(0.1 \%$ NHLs) in the Czech Lymphoma Study Group database. DLBCL was the most frequent histology subtype (50\%), and ALCL was identified in $12.5 \%$ of cases. At initial diagnosis, the median age was 55.5 (range 21-74) years and 59\% were men. None of the 16 patients with cardiac involvement had isolated heart lymphoma. The response to first-line therapy was $79 \%$ in 14/16 evaluable patients. The median progression-free survival and overall survival were nearly the same approximately 3.5 years (range; 0.05-16.7ys), while the median follow up was 4 years.
\end{abstract}

Keywords: cardiac lymphoma; anaplastic large cell lymphoma; ALK

\section{Introduction}

Anaplastic large cell lymphoma (ALCL) is a rare subtype of non-Hodgkin's lymphoma (NHL) representing about $5 \%$ of all NHLs in adults and about $15 \%$ in children [1]. Morphology is characterized by anaplastic large cell mature $T$ lymphocytes that express the lymphocyte activation marker CD30 and epithelial membrane antigen (EMA) [2]. According to the presence of anaplastic lymphoma kinase (ALK) translocation, two different entities are distinguished: ALK-positive and ALK-negative ALCL [3]. ALK is a receptor protein-tyrosine kinase and its aberrant activations are involved in several human malignancies. The rearrangement partners of ALK could be different: the first partner identified and most recurrent is nucleophosmin (NPM1) mutations and involves t(2:5)(p23:q35) [4, 5].

Systemic ALCL has an aggressive clinical course with nodal or extranodal involvement. Skin, soft tissue, liver, lungs and bone are the most common extranodal sites of involvement in ALK+ ALCL [1]. ALK+ ALCL represents about $65-80 \%$ of

*Corresponding author: Andrea Janikova, MD, PhD, Ast. Prof. Department of Internal Medicine - Hematology and Oncology, Masaryk University and University Hospital Brno, Jihlavska 20, 62500 Brno, Czech Republic, Tel.: +420 53223 3642; Fax: +420 53223 3603; Email: janikova.andrea@fnbrno.cz

Received 17 September 2017 Revised 18 October 2017 Accepted 27 October 2017 Published 2 November 2017

Citation: Lobello C, Janikova A, Kren L, Hermanova M, Sprlakova-Pukova A, Krejci J, Pospisilova S, Pytlik R, Hamouzova M, Belada D, Prochazka V, Duras J, Mocikova $H$, Trneny M. An anaplastic cardiac large cell lymphoma: A case report and analysis of cardiac involvement in newly diagnosed non-Hodgkin's lymphoma from the Czech Lymphoma Study Group (CLSG) database. J Cancer Res Ther. 2017; 5(10):66-71. DOI: 10.14312/20524994.2017-13

Copyright: (c) 2017 Lobello C, et al. Published by NobleResearch Publishers. This is an open-access article distributed under the terms of the Creative Commons Attribution License, which permits unrestricted use, distribution and reproduction in any medium, provided the original author and source are credited. 
ALCLs depending on age $[1,6]$. ALK+ ALCL typically affects young patients ( $<40$ years), mostly male, while ALK- ALCL is found in older patients (median age approximately 50 years) of both sex. Overall, ALK+ ALCL has a more favorable prognosis than ALK- ALCL, with 5-year overall survival (OS) of $70 \%$ and $49 \%$, respectively [7].

Cardiac involvement (primary or secondary) by malignant lymphoma is uncommon and pre-death diagnosis is sometimes difficult, in particular when there are no cardiac manifestations [8]. Cardiac lymphomas are infiltrative, intramural, and epicardial lesions that may be singular or multiple, and pericardium is involved in about a third of cases. Secondary cardiac involvement by lymphoma was discovered in almost $10-25 \%$ of patients with advanced disease [8-10]. Primary cardiac lymphoma is extremely rare and accounts for less than $2 \%$ of all resected primary cardiac tumors and $0.5 \%$ of extranodal lymphomas at autopsy [9-11]. The incidence of primary cardiac lymphoma is thought to be increasing in recent years due to access to advanced imaging modalities and surgical techniques. Cardiac lymphomas preferable involve the right side of the heart, especially the right atrium [13]. Clinical manifestation reflects the anatomical site and includes arrhythmias, heart failure, angina/chest pain, vena cava superior syndrome, etc. $[13,14]$. On the other hand, about $30 \%$ of autopsyproven secondary cardiac lymphomas only develope some clinical symptomatology [8].

Herein, we report the rare case of a 59-year-old male with cardiac ALK+ ALCL. We found some case reports on cardiac ALCLs in children or very young people in the literature [15-19]. We added the retrospective analysis of cardiac involvement in newly diagnosed lymphomas based on data from the Czech Lymphoma Study Group (CLSG) database, as most reported incidence of cardiac lymphoma was derived from the autopsies of patients with advanced disease or a set of cardiac tumors [8-11].

\section{Case report}

A 59-year-old man with newly diagnosed ALK+ ALCL was referred to our department in November 2015. The diagnosis was made from the rapidly growing right axillar lymphadenopathy in August 2015 (3 months earlier). Unilateral axillar lymphadenopathy was the only clinical manifestation of lymphoma. Within the routine staging, the $\mathrm{CT}$ revealed some pathological content of the right heart ventricle (around $4 \times 3 \mathrm{~cm}$ ). Apart from the right axilla and cardiac abnormity, no other lymphadenopathy or infiltration was found. The unilateral trephine biopsy was done without histological evidence of lymphoma.

The patient was a heavy drinker in the past and suffered from mild toxonutritive hepatitis and steatosis. In 2015, a cholecystectomy was performed and he developed a pulmonary embolism. Low-molecular heparin therapy was subsequently administered.

Laboratory tests determined a normal blood count including microscopic white count, while there was mild elevation of $\mathrm{LDH}$ (5.5 ukat/l), borderline elevation of CRP (9.2 mg/l) and mild hyperuricemia (351 umol/l). A 12-lead ECG identified a completely normal record. HIV serology was negative.
Echocardiography $(\mathrm{ECHO})$ revealed the formation in the right ventricle cavity going to the right ventricular apex (total size of $5.4 \times 2.9 \mathrm{~cm}$ ) and also involving the septal wall. Heart function was normal with a left ventricle ejection fraction of about $55-60 \%$. The left ventricle showed no hypertrophy or dilatation; the right ventricle was enlarged with good contractility. As there was no possibility (including cardiac MRI) to distinguish between myxoma from other tumors (Figure 1), the patient underwent an endomyocardial biopsy (performed without complications on November 26, 2015). The histological examination of 10 myocardial samples confirmed infiltration by CD30+, ALK+, CD20- lymphoma with high proliferation activity (Ki67 $90 \%)$. The finding was consistent with an anaplastic large cell lymphoma ALK+. Clinical stage IIE, with right axillar and cardiac involvement was therefore concluded.

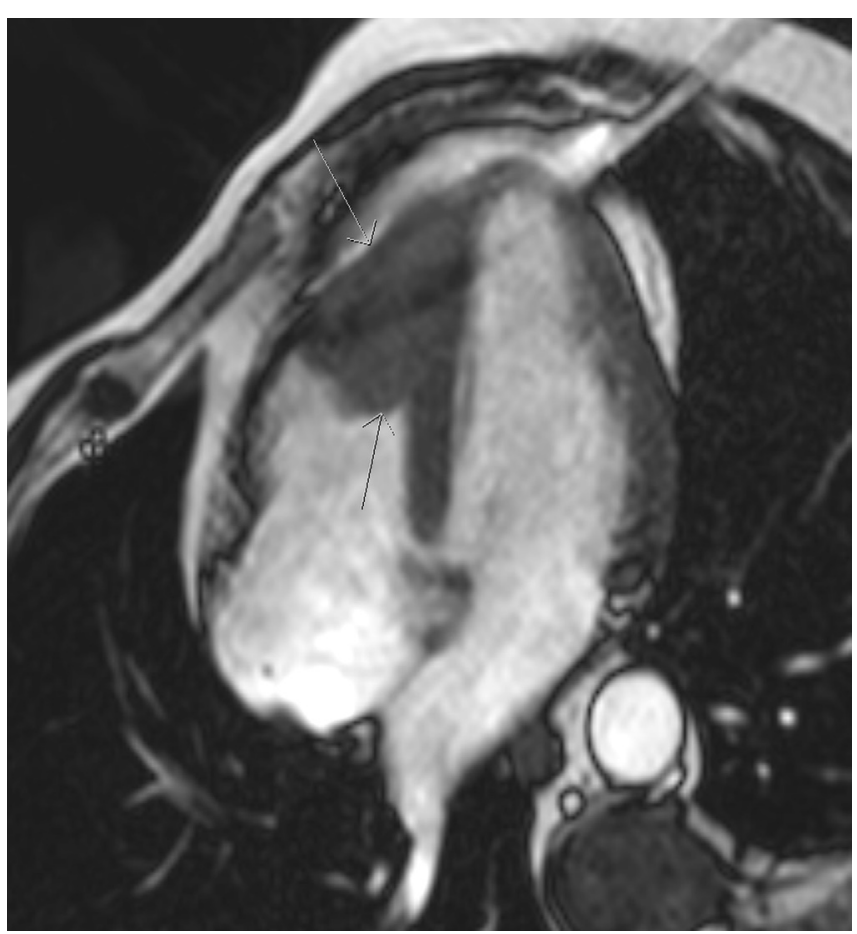

Figure 1 Cardiac MRI scan - no possibility to distinguish between myxoma from other tumors.

Induction therapy consisting of six cycles of CHOP (cyclophosphamide $750 \mathrm{mg} / \mathrm{m}^{2}$, doxorubicine $50 \mathrm{mg} / \mathrm{m}^{2}$, vincristine $2 \mathrm{mg}$ absolute dose, and prednisone $100 \mathrm{mg} /$ day for 5 days) was started. The first cycle was administered under continual monitoring in the intensive care unit. No complications during or after chemotherapy administration were observed, and the patient was discharged 5 days after the start of therapy. The following treatment was fully continued as an outpatient with regular ECHO monitoring. As the ejection fraction decreased (from $60 \%$ to 50\%), the last cycle of chemotherapy was changed to CEOP with the replacement of doxorubicine by etoposide. Restaging by CT/PET after the completion of chemotherapy (May 2016) showed a complete response. The last follow up in late March 2017 confirmed continuing remission.

Cardiac lymphoma incidence - analysis of Czech Lymphoma Study Group (CLSG) database

The prospectively maintained multi-centric CLSG database covers more than $85 \%$ of all newly diagnosed adult 
NHLs in the Czech Republic as previously described [20]. Participating sites are university hospitals and large oncology centers. Patients signed an Informed Consent Form before the data was entered into the CLSG database. There was a local pathological assessment, which was reviewed by experienced hemopathologists in university centers. Moreover, a central pathological review of samples or at least local pathological reports was made in approximately half of the patients. Treatment and outcomes including response, time to progression, and survival are collected annually, and patients are followed until death, withdrawal of consent, or loss of follow up. The patient stage was determined by the treating physician according to the Ann Arbor criteria, and more recently CLSG staging recommendations has been used [21-24]. Initial rigorous staging included at least a thoracic and abdominal CT scan, and unilateral bone marrow biopsy. PET or PET/CT has only been used in recent years. A complete blood count and LDH level were performed and recorded in the database.
At the time of this retrospective analysis (August 2016), there were 13,362 NHL patients diagnosed between 1999 and 2016, registered in the CLSG database with completed staging data. Some extranodal involvement was identified in 9,764 patients, including 99 patients with infiltration of pericardium $(0.7 \%)$, and 16 patients (around $0.1 \%$ ) with direct infiltration of the heart. Interestingly, none of these 16 patients with cardiac involvement had isolated heart lymphoma (= primary cardiac lymphoma). Three of the 16 patients with secondary cardiac involvement also had infiltrated pericardium. The majority of patients had elevated serum lactate dehydrogenase (15/16), and 9/16 developed systemic symptoms, whereas $8 / 16$ patients had performance status $\geq 2$. The median age was 55.5 years (range $21-74$ years), with a preponderant proportion of men $(10 / 16 ; 62.5 \%)$. DLBCL was the most frequent histology subtype $(8 / 16 ; 50 \%)$, but ALCL was identified in $2 / 16(12.5 \%)$ cases. An overview of the basic characteristics of all lymphoma patients with cardiac involvement is shown in Table 1.

Table 1 Basic clinical characteristics of lymphoma patient with cardiac involvement.

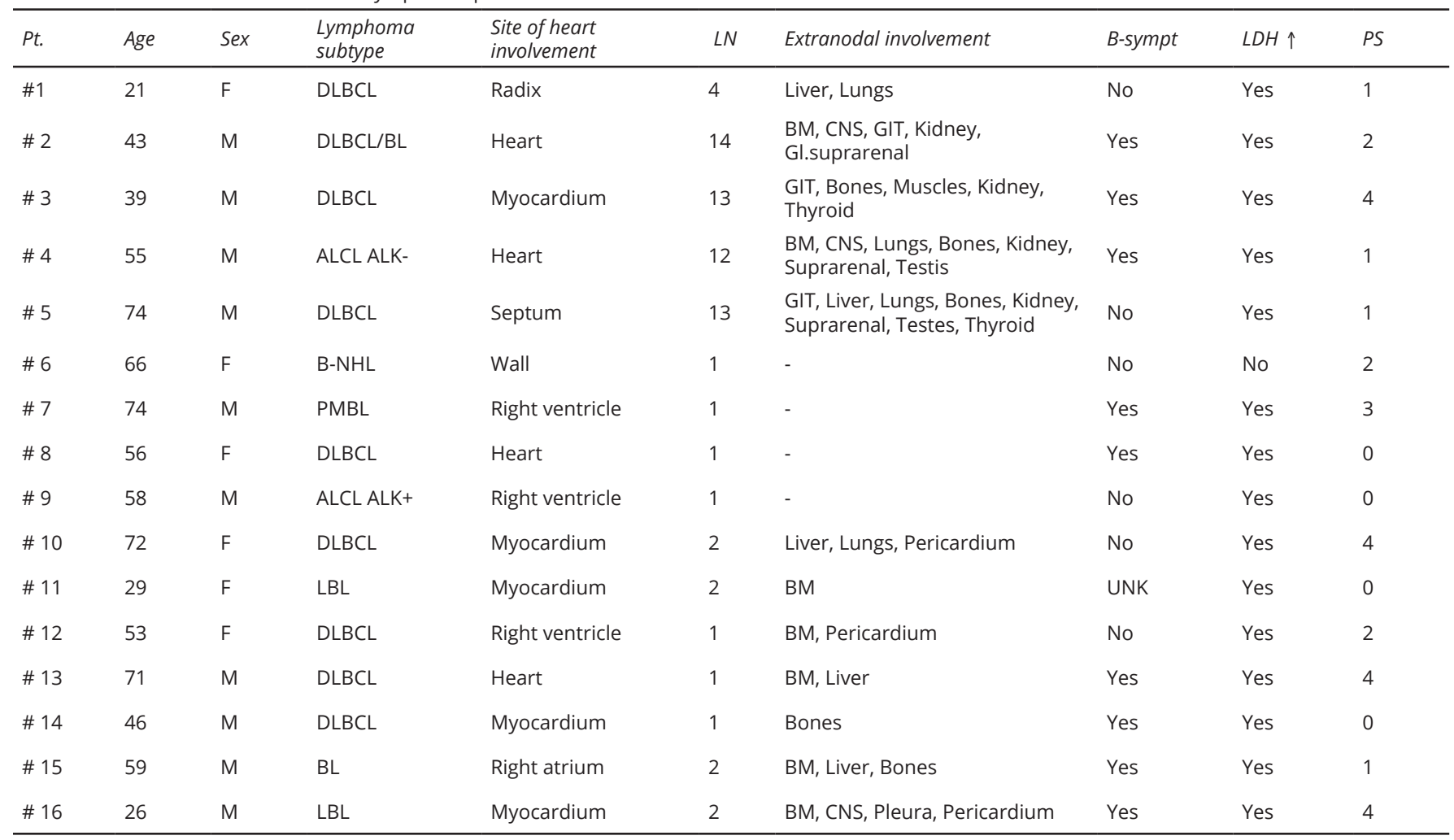

Abbreviations: DLBCL - Diffuse large B-cell lymphoma, BL - Burkitt lymphoma, B-NHL - B-NonHodgkin lymphoma, PMBL - Primary mediastinal B-cell lymphoma, LBL - Lymphoblastic lymphoma, M - Male, F - female, LN - lymphonode, BM - Bone marrow, CNS - Central nervous system, GIT - Gastrointestinal tract, LDH - Lactate dehydrogenase, PS - Performance status.

The median follow up of this small cohort of patients is nearly 4 years. Patients were treated with CHOP-like regimens in 8 cases, 6 patients received more aggressive conventional therapy (e.g. CHOP/HyperCVAD/HD-MTX, CODOX-M/IVAC, etc.), and 3 patients were consolidated with high-dose chemotherapy with autologous stem cell transplantation. A response to first-line therapy was evaluable in $14 / 16$ patients, with $11 / 14(79 \%)$ remissions, including 8 complete responses (Table 2). There were $6 / 16$ progressions and 5/16 deaths during the follow up; progressions are tightly associated with death. Median progression-free survival and overall survival are nearly the same: 3.2 and 3.5 years (range; 0.05-16.7 years), respectively.

\section{Discussion}

$A L C L$ is a very rare lymphoma and the ALK positive subtype accounts for approximately 3\% of adult NHLs and 10-20\% of childhood lymphomas [3]. The proportion of ALK+ lymphoma among adult ALCLs varies $12-40 \%$ depending on age [25]. We found a few case reports of cardiac involvement with $A L C L$, all of which occurred in patients between 8 and 29 years of age [15-19]. All these cases 
Table 2 Overview of therapy and survival results in patients with heart lymphoma involvement.

\begin{tabular}{|c|c|c|c|c|c|c|c|c|c|c|}
\hline Pt & Age & $\begin{array}{l}\text { Lymphoma } \\
\text { subtype }\end{array}$ & Chemotherapy & Radiotherapy & $T x$ & Response & Progression & Death & $\begin{array}{l}\text { PFS } \\
\text { years }\end{array}$ & $\begin{array}{l}\text { OS } \\
\text { years }\end{array}$ \\
\hline$\# 1$ & 21 & DLBCL & MegaCHOP, ESHAP & Yes & Yes & $\mathrm{CR}$ & No & No & 14.6 & 14.6 \\
\hline \# 3 & 39 & DLBCL & CHOP/HyperCVAD/HD-MTX & 0 & 0 & $\mathrm{CR}$ & No & No & 3.9 & 3.9 \\
\hline \# 4 & 55 & ALCL ALK- & CHOP/HyperCVAD/HD-MTX & 0 & 0 & $\mathrm{CR}$ & Yes & No & 2.7 & 3.37 \\
\hline \# 5 & 74 & DLBCL & $\mathrm{CHOP}$ & 0 & 0 & PR & No & No & 0.7 & 0.7 \\
\hline \# 6 & 66 & B-NHL & $\mathrm{CHOP}$ & 0 & 0 & CR & No & No & 16.7 & 16.7 \\
\hline$\# 7$ & 74 & PMBL & CHOP & Yes & 0 & CR & Yes & Yes & 9.98 & 9.98 \\
\hline$\# 8$ & 56 & DLBCL & CHOP & 0 & 0 & $\mathrm{CR}$ & No & No & 4.7 & 4.7 \\
\hline \# 9 & 58 & ALCL ALK+ & CHOP/CEOP & 0 & 0 & $\mathrm{CR}$ & No & No & 0.68 & 0.68 \\
\hline \# 11 & 29 & LBL & UNK & UNK & UNK & UNK & No & No & UNK & UNK \\
\hline \# 12 & 53 & DLBCL & $\mathrm{CHOP}$ & Yes & 0 & PR & No & No & 3.7 & 3.7 \\
\hline \# 13 & 71 & DLBCL & CHOP/HD-MTX & 0 & 0 & Progression & Yes & Yes & 0.5 & 0.5 \\
\hline \# 14 & 46 & DLBCL & SEQ protokol & 0 & Yes & PR & Yes & Yes & 1.47 & 2.3 \\
\hline \# 15 & 59 & $\mathrm{BL}$ & CODOX-M/IVAC & 0 & 0 & $\mathrm{CR}$ & No & No & 3.84 & 3.84 \\
\hline \# 16 & 26 & LBL & HyperCVAD/HD- MTX/AraC & 0 & 0 & UNK & No & No & UNK & UNK \\
\hline
\end{tabular}

Abbreviations: DLBCL - Diffuse large B-cell lymphoma, BL - Burkitt lymphoma, B-NHL - B-NonHodgkin lymphoma, PMBL - Primary mediastinal B-cell lymphoma, LBL - Lymphoblastic lymphoma, UNK - Unknown, Tx - Stem cell transplantation, CR - Complete remission, PR - Partial remission, CHOP - (Cyclophosphamide 750mg/m2 D1, Doxorubicine 50mg/m2 D1, Vincristine 2mg abs.dose D1, Prednisone 100mg D1-D5), MegaCHOP - (Cyclophosphamide 2000-3000mg/m2 D1, Doxorubicine 75mg/m2 D1, Vincristine 2mg abs.dose D1, Prednisone 60mg/m2 D1-D5), ESHAP - (Etoposide 60mg/m2 D1-D4, Cisplatinum 25mg/m2 D1-D4, Cytosine-arabinoside 2000mg/m2D5, Methylprednisolone 500mg D1-D4), HyperCVAD /HD-MTX/AraC - (Cyclophosphamide 600mg/m2 D1-D3, Doxorubicine $50 \mathrm{mg} / \mathrm{m} 2 \mathrm{D} 4$, Vincristine $2 \mathrm{mg}$ abs.dose D4 and D11, Dexamethasone 40mg abs.dose D1-D4 and D11-D14, Methotexate 1000mg/m2 D1, Cytosine-arabinoside 6000mg/m2 D2-D3), CODOX-M - (Cyclophosphamide 800mg/m2 D1-D2, Doxorubicine 50mg/m2 D1, Vincristine 2mg abs.dose D1, Methotrexate 3000mg/m2 D10), IVAC - (Etoposide 60mg/m2 D1-D5, Ifosfamide 1500mg/m2 D1-D5, Cytosine-arabinoside 4000mg/m2 D1-D2), HD-MTX - (Methotrexate 2000mg/m2), CEOP - (Cyclophosphamide 750mg/m2 D1, Etoposide100mg/m2 D1-D3, Vincristine 2mg abs.dose D1, Prednisone 100mg D1-D5), SEQ - Consisted of 3 cycles of PACEBO (doxorubicine, cyclophosphamide, etoposide, bleomycine, vincristine, and prednisone), 1 cycle of IVAM (ifosfamide, etoposide, cytosine-arabinoside, and methotrexate), 1 cycle of HAM (high-dose cytosine-arabinoside, and mitoxantrone) and consolidation with high-dose BEAM with autologous stem cell support.

were ALCL ALK+, and only one report showed localized (= primary) cardiac lymphoma [15]. In all published cases, the cardiac involvement was identified based on clinical symptoms (syncopal episode, arrhythmia, heart failure). In comparison to published reports, our case is atypical because of the relatively advanced age of manifestation
(> 50 years), and also because of the involvement which is neither primary cardiac nor exclusively advanced (heart and left axilla only). Moreover, the cardiac involvement was clinically entirely asymptomatic and discovered randomly. An overview and comparison of all published ALCL cases with cardiac involvement are summarized in Table 3.

Table 3 Overview of published case reports of cardiac ALCL.

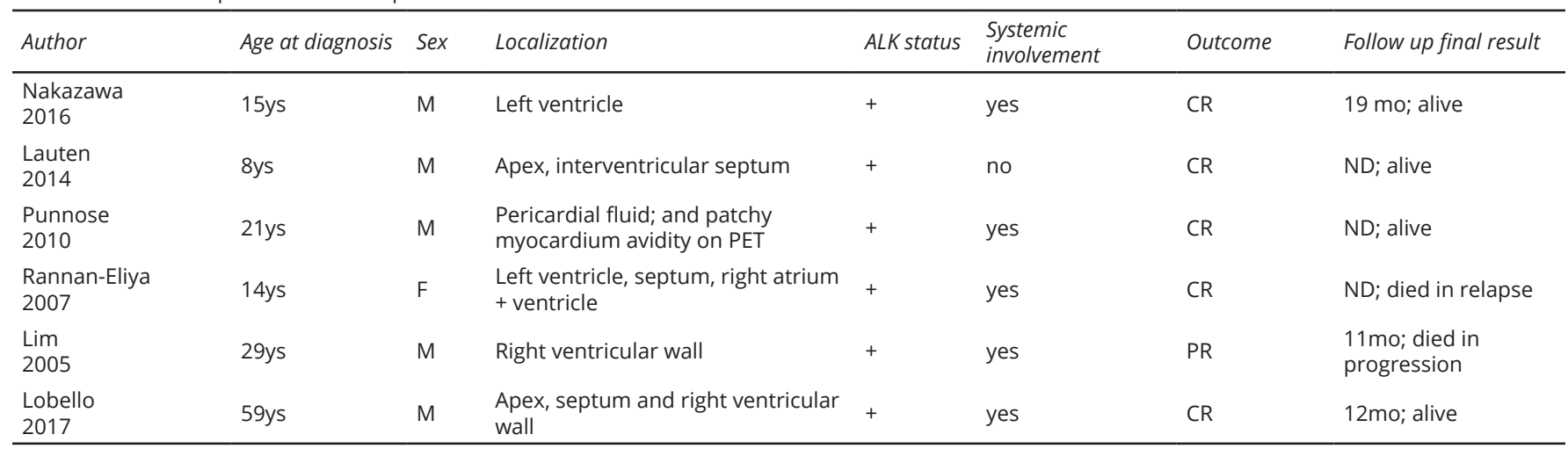

Abbreviations: M - Male, F - Female, CR - Complete remission, PR - Partial remission, ND - Not done.

Generally, cardiac tumors are rare diseases, and the most common tumors that involve the heart are metastatic neoplasms. Cardiac lymphomas occur mostly in the frame of systemic lymphoma progression, and are observed mainly at a late phase of the advanced disease. Post- mortem studies show that cardiac involvement by lymphoma is present in $16 \%$ of patients with Hodgkin's lymphoma and $18 \%$ of patients with NHL [26]. Our results from the CLSG registry showed a much lower incidence of cardiac involvement (about $0.1 \%$ ) in all patients with 
NHL. This difference is caused by the time of evaluation, whereas the CLSG registry presents the incidence at the time of initial lymphoma diagnosis, published reports operated with data from autopsies of patients who died due to lymphoma (advanced and recurrent) [8, 26]. Primary cardiac lymphomas involving heart and pericardium are very uncommon - less than $2 \%$ of primary cardiac tumors [27]. There is no clear definition of primary cardiac lymphoma and the WHO classification of tumors and hematopoietic and lymphoid tissues does not acknowledge primary cardiac lymphoma as a distinct entity [3]. Carras et al., recently published 13 cases of primary cardiac lymphoma in newly diagnosed lymphoma in a single-institution retrospective study, but $69 \%$ of them also had other extracardiac involvement. Moreover, the algorithm to identify cardiac lymphoma was the use of a set of keywords "pericardium, myocardium and cardiac" to screen the population of interest [14]. For this reason, it would be difficult to assess the real incidence of lymphoma involvement of the heart among lymphoma patients in such a study. Interestingly, no primary cardiac lymphoma (= cardiac involvement only) was identified in the CLSG database.

The main histological subtype is usually represented by B-cell lineage, in particular diffuse large B-cell lymphoma (DLBCL) in approximately $80-90 \%$ cases [8, 9, 14, 28]. The data from our database confirms preponderant involvement by DLBCL (8/16 cases; $50 \%)$, eventually with 2 additional cases with DLBCL/BL and PMBL (10/16; 66\%), which corresponds with the high global incidence of DLBCL in the Czech Republic (40-45\% of all NHLs). On the other hand, in our dataset there were 2/16 (12.5\%) cases of ALCL (one ALK+ and one ALK-) with cardiac involvement, which is a much higher proportion compared to the ALCL/ DLBCL ratio (3-5\%) among all NHLs in adults. In accordance with published data, our case of ALCL impaired the right heart, which is the most common place of involvement [14]. Contrarily, we cannot assess the frequency of heart locality from the CLSG registry, as our data was not precise enough (clearly defined right ventricle infiltration was only defined in 4 cases).

The overall prognosis of cardiac lymphomas, either primary or secondary involvement, depends on three factors: 1) subtype of lymphoma; 2) global extent of disease; 3) cardiac damage/symptoms. Based on our survival data, we can conclude that about half of patients with cardiac involvement survive for a long time in their first remission (median 3.5 years; follow up 4 years). The majority of patients have potentially curative subtypes of lymphoma (DLBCL, ALCL ALK+, BL) and can be cured. Our case also supports the evidence that systemic therapy (chemotherapy based) is an efficient and safe modality for how to manage cardiac lymphoma, especially in asymptomatic patient. Nevertheless, cardiac involvement is a feared finding; we cannot see it as an exclusively critical event in lymphoma.

\section{Conclusion}

To our knowledge, this is the first report mapping the real incidence of cardiac involvement in an unselected population of adult patients with newly diagnosed NHL. Our data is in concordance with published data in this area, and supports the evidence of good chemotherapy tolerance and efficacy. Our report aims to shed more light on ALCL with cardiac involvement and to contribute to clinical records for better clarification and understanding of the behavior and biology of this specific and rare disease manifestation.

\section{Acknowledgements}

This project has received funding from the European Union's Horizon 2020 Research and Innovation Programme under the [Marie Skłodowska-Curie grant agreement No 675712; ALKATRAS], from the project CEITEC 2020 [LQ1601] and grant [AZV CR 16-31092A] supported by the Ministry of Education, Youth and Sports of the Czech Republic, and the University Hospital Brno institutional support [MZ ČRRVO FNBr, 65269705].

\section{Conflicts of interest}

Authors declare no conflicts of interest.

\section{References}

[1] Falini B, Pileri S, Zinzani PL, Carbone A, Zagonel V, et al. ALK+ lymphoma: Clinicopathological findings and outcome. Blood. 1999; 93(8):26972706.

[2] Stein H, Foss HD, Dürkop H, Marafioti T, Delsol G, et al. CD30+ anaplastic large cell lymphoma: A review of its histopathologic, genetic, and clinical features. Blood. 2000; 96(12):3681-3695.

[3] Delsol G, Falini B, Muller-Hermelink HK, Campo E, Jaffe ES, et al. Anaplastic large cell lymphoma, ALK-positive. In: Swerdlow SH, Campo $\mathrm{E}$, Harris NL, Jaffe ES, Pileri SA, Stein H, editors. WHO Classification of Tumours of Haematopoietic and Lymphoid Tissues. Lyon: International Agency for Research on Cancer; 2008:312-316.

[4] Rimokh R, Magaud JP, Berger F, Samarut J, Coiffier B, et al. A translocation involving a specific breakpoint (q35) on chromosome 5 is characteristic of anaplastic large cell lymphoma ('Ki-1 lymphoma'). Br J Haematol. 1989; 71(1):31-36.

[5] Morris SW, Kirstein MN, Valentine MB, Dittmer KG, Shapiro DN, et al. Fusion of a kinase gene, ALK, to a nucleolar protein gene, NPM, in nonHodgkin's lymphoma. Science. 1994; 263(5151):1281-1284.

[6] Jaffe ES. Anaplastic Large Cell Lymphoma: The Shifting Sands of Diagnostic Hematopathology. Mod Pathol. 2001; 14(3):219-228.

[7] Savage KJ, Harris NL, Vose JM, Ullrich F, Jaffe ES, et al. ALK- anaplastic large-cell lymphoma is clinically and immunophenotypically different from both $A L K+A L C L$ and peripheral T-cell lymphoma, not otherwise specified: Report from the International Peripheral T-Cell Lymphoma Project. Blood. 2008; 111(12): 5496-504.

[8] Chinen K, Izumo T. Cardiac involvement by malignant lymphoma: A clinicopathologic study of 25 autopsy cases based on the WHO classification. Ann Hematol. 2005; 84(8):498-505.

[9] Burke A, Tavora F. The 2015 WHO Classification of Tumors of the Heart and Pericardium. J Thorac Oncol. 2016; 11(4):441-452.

[10] Gowda RM, Khan IA. Clinical perspectives of primary cardiac lymphoma. Angiology. 2003; 54 (5):599-604.

[11] Patel J, Sheppard MN. Pathological study of primary cardiac and pericardial tumours in a specialist UK Centre: Surgical and autopsy series. Cardiovasc Pathol. 2010; 19:343-352.

[12] Travis WD, Brambilla E, Burje AP, Marx A, Nicholson AG. WHO classification of tumours of the lung, pleura, thymus and heart. 4th edition. 2015.

[13] Jeudy J, Burke AP, Frazier AA. Cardiac Lymphoma. Radiol Clin North Am. 2016; 54(4):689-710.

[14] Carras S, Berger F, Chalabreysse L, Callet-Bauchut E, Cordier JF, et al. Primary cardiac lymphoma: Diagnosis, treatment, and outcome in modern series. Hematol Oncol. 2016. 
[15] Lauten M, Vieth S, Hart S, Wössmann W, Tröger B, et al. Cardiac anaplastic large cell lymphoma in a 8-year old boy. Leuk Res Rep. 2014; 3(2):36-37.

[16] Lim ZY, Grace R, Salisbury JR, Creamer D, Jayaprakasam A, et al. Cardiac presentation of ALK positive anaplastic large cell lymphoma. Eur J Haematol. 2005; 75(6):511-514.

[17] Hirabayashi K, Yamauchi S, Matsuzaki S, Komatsu K, Sano K, et al. Anaplastic large-cell lymphoma of the left ventricle presenting with arrhythmia and cerebral infarction due to cardiogenic embolism. Pediatr Blood Cancer. 2016; 63(4):755-756.

[18] Rannan-Eliya YF, Pulford K, Johnson R, Peart I, Kokai G, et al. Isolated cutaneous anaplastic large cell lymphoma progressing to severe systemic disease with myocardial involvement and central nervous infiltration. Pediatr Blood Cancer. 2008; 50(4):879-881.

[19] Punnoose LR, Roh JD, Hu S, Udell JA, Wagle N, et al. Cardiac presentation of anaplastic large-cell lymphoma. J Clin Oncol. 2010; 28(19):e314e316.

[20] Janikova A, Bortlicek Z, Campr V, Kopalova N, Benesova K, et al. Impact of rituximab maintenance and maintenance schedule on prognosis in first-line treatment of follicular lymphoma. Retrospective analysis from Czech Lymphoma Study Group (CLSG) database. Leuk Lymphoma. 2016; 57(5):1094-1103.

[21] Carbone PP, Kaplan HS, Musshoff K, Smithers DW, Tubiana M. Report of the committee on no Hodgkin's disease staging classification. Cancer Res. 1971; 31(11):1860-1861.

[22] Sykorova A, Belada D, Smolej L, Pytlík R, Benesová K, et al. Staging of non-Hodgkin's lymphoma -recommendations of the Czech Lymphoma Study Group. Klin Onkol 2010; 23(3):146-154.

[23] Cheson BD, Pfistner B, Juweid ME, Gascoyne RD, Specht L, et al. Revised response criteria for malignant lymphoma. J Clin Oncol. 2007; 25(5):579-586.

[24] Cheson BD, Fisher RI, Barrington SF, Cavalli F, Schwartz LH, et al. Recommendations for initial evaluation, staging, and response assessment of Hodgkin and non-Hodgkin lymphoma: The Lugano classification. J Clin Oncol. 2014; 32(27):3059-3068.

[25] Janikova A, Pytlik R, Klener P, Bortlicek Z, Campr V, et al. Populationbased analysis of elderly patients ( $>70$ years) with peripheral T-cell lymphoma: A results from Czech Lymphoma Study Group (CLSG) Registry. ASH Annual meeting. 2016.

[26] O'Mahony D, Peikarz RL, Bandettini WP, Arai AE, Wilson WH, et al. Cardiac Involvement with Lymphoma: A Review of the Literature. Clin Lymphoma Myeloma. 2008; 8(4):249-252.

[27] Fernandes F, Soufen HN, lanni BM, Arteaga E, Ramires FJ, et al. Primary neoplasms of the heart: Clinical and histological presentation of 50 cases. Arq Bras Cardiol. 2001; 76(3):231-237.

[28] Chemello D, Raupp-da-Rosa P, Teló G, Clausell N. Ventricular tachycardia associated with non-Hodgkin's lymphoma. Arq Bras Cardiol. 2011; 97(6):e132-134. 